Document downloaded from:

http://hdl.handle.net/10251/101858

This paper must be cited as:

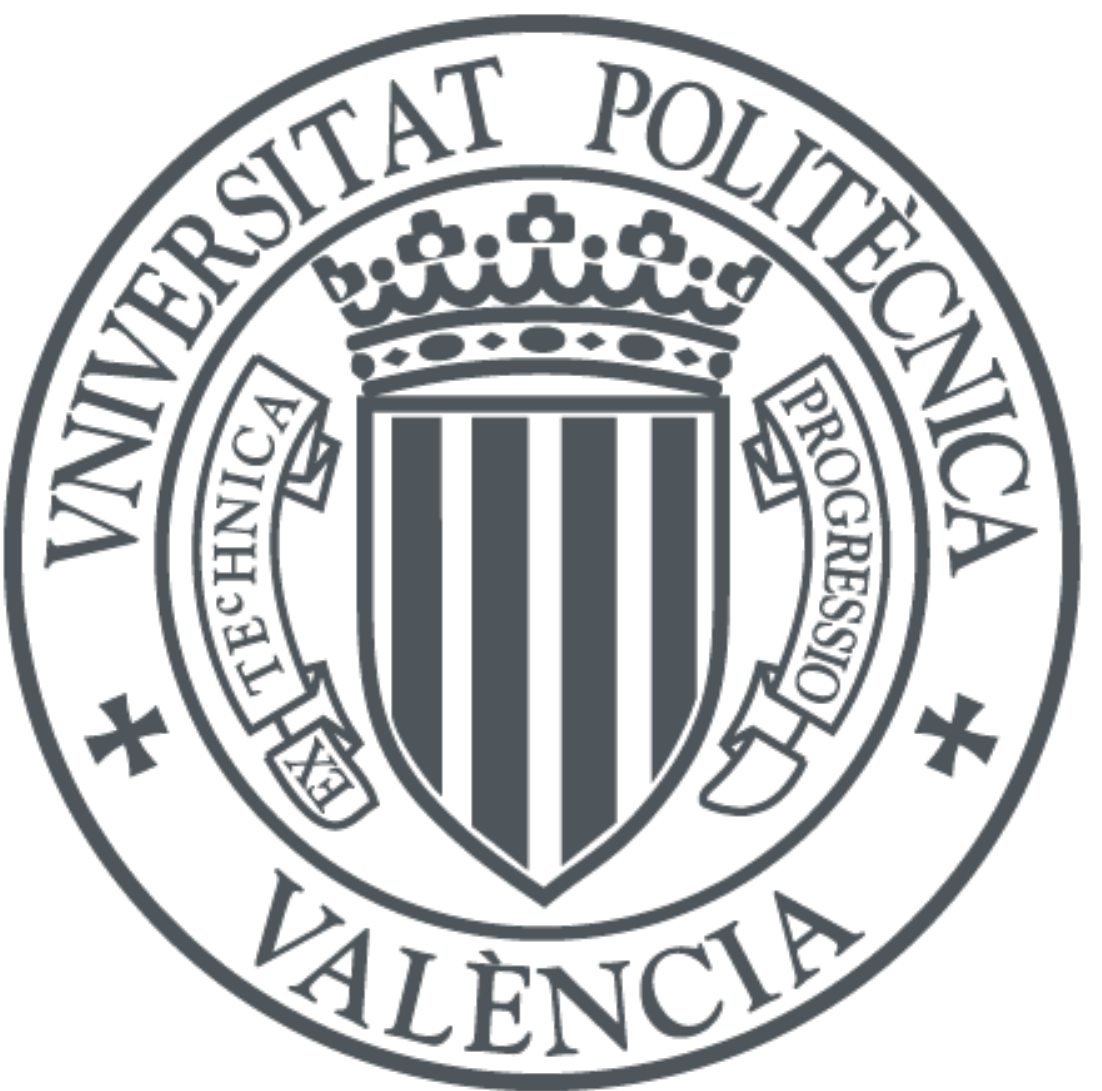

The final publication is available at

https://doi.org/10.1007/s11051-017-4077-2

Copyright Springer-Verlag

Additional Information 


\title{
A study of some fundamental physicochemical variables on the morphology of mesoporous silica nanoparticles MCM-41 type
}

\author{
Ángela A. Beltrán-Osuna a, José L. Gómez Ribelles ${ }^{\text {b,c }}$, Jairo E. Perilla ${ }^{\text {a,* }}$ \\ ${ }^{a}$ Grupo de Procesos Químicos y Bioquímicos, Departamento de Ingeniería Química y \\ Ambiental, Universidad Nacional de Colombia - KR 3045 03, 111321, Bogotá, \\ Colombia. \\ ${ }^{\mathrm{b}}$ Centre for Biomaterials and Tissue Engineering, Universitat Politècnica de València, \\ Camino de Vera s/n, Edificio 8E, 46071 Valencia, España. \\ ${ }^{\mathrm{c}}$ Biomedical Research Networking Center in Bioengineering, Biomaterials and \\ Nanomedicine (CIBER-BBN), Spain \\ *Corresponding Author: E-mail: jeperillap@unal.edu.co Tel: +57(1)3165321 ORCID: \\ 0000-0002-9489-6260
}




\begin{abstract}
All variables affecting the morphology of Mesoporous Silica Nanoparticles (MSN) should be carefully analyzed in order to truly tailored design their mesoporous structure according to their final use. Although complete control on MCM-41 synthesis has been already claimed, reproducibility and repeatability of results remain a big issue due to the lack of information reported in literature. Stirring rate, reaction volume and system configuration (i.e. opened or closed reactor), are three variables that are usually omitted, making difficult the comparison of product characteristics. Specifically, the rate of solvent evaporation is seldom disclosed, and its influence has not been previously analyzed. These variables were systematically studied in this work and they were proven to have a fundamental impact on final particle morphology. Hence, a high degree of circularity $(\mathrm{C}=0.97)$ and monodispersed particle size distributions were only achieved when a stirring speed of $500 \mathrm{rpm}$ and a reaction scale of $500 \mathrm{~mL}$ were used in a partially opened system, for a two hours reaction at $80^{\circ} \mathrm{C}$. Well-shaped spherical mesoporous silica nanoparticles with a diameter of $95 \mathrm{~nm}$, a pore size of $2.8 \mathrm{~nm}$, and a total surface area of $954 \mathrm{~m}^{2} \mathrm{~g}^{-1}$ were obtained. Final characteristics made this product suitable to be used in biomedicine and nanopharmaceutics, especially for the design of drug delivery systems.
\end{abstract}

Keywords: MSN, partially opened system, reaction volume, stirring rate, MCM-41. 


\section{Introduction}

Mesoporous Silica Nanoparticles (MSN) are spherical silica particles with diameters smaller than $200 \mathrm{~nm}$, and pore sizes ranging from 2 to $50 \mathrm{~nm}$ (IUPAC 2014). The most common type is known as MCM-41 (Mobile Catalytic Material No. 41) and it is conventionally synthesized by hydrolysis-condensation reactions of tetraethyl orthosilicate (TEOS), in the presence of a surfactant (Kresge et al. 1992). The packing of surfactant micelles in solution provides the template for the mesoporous structure of MSN. Then, a highly ordered mesostructure of unidirectional cylindrical channels organized in hexagonal arrangements is formed inside the particles, which provides them with very high surface areas $\left(1000 \mathrm{~m}^{2} \mathrm{~g}^{-1}\right.$ ) and pore volumes (from 0.5 to $2 \mathrm{~cm}^{3} \mathrm{~g}^{-1}$ ) (Yang and $\mathrm{Yu}$ 2015). One of the most promising applications for these unique characteristics are in the biomedical and nanopharmaceutical fields, including: biosensoring (Zhang et al. 2015), biological imaging (Chen et al. 2015a; Xu et al. 2015a, 2016), gasotransmitters (Chakraborty and Mascharak 2016), tissue engineering (Chen et al. 2013), gene transfer (Brevet et al. 2014), vaccine adjuvants (Oliveira et al. 2016) and, particularly drug delivery systems. In this field, latest advances includes MSN functionalization with polyelectrolytes (Varga et al. 2015), lipid bilayers (Han et al. 2016), and polymeric shells (Hu et al. 2014; Xu et al. 2015b), or mechanized MSN with different gate keepers (Cheng et al. 2016; Rafi et al. 2016; Xu et al. 2016), PAMAM dendrimers (Xu et al. 2015a) or $\beta$-cyclodextrin (Chen et al. 2015b) for the design of pH-responsive delivery vehicles, notably for cancer treatment (Cheng et al. 2016; Han et al. 2016; Hu et al. 2014; Rafi et al. 2016; Xu et al. 2015b). Excellent reviews may be found illustrating a variety of novel synthesis technologies for MSN and their most promising and leading-edge applications in biomedicine (Beltrán-Osuna and Perilla 2016; Sun et al. 2015; Wang et al. 2015).

MSN were proposed for the first time as a drug delivery system in 2001 (Vallet-Regi et al. 2001) and, since then, reports have been exponentially growing, but only until 2008 MSN started to be use in vitro and in vivo assays on animals (Chen et al. 2013). 
Recently, silica spheres of $6 \mathrm{~nm}$, surface-functionalized with PEG (polyethylene glycol) chains and peptides were synthesized (Phillips et al. 2014). These are known as C-dots (Cornell dots), the first nanoparticle approved by the FDA tested in human trials, and the only one that has been used in clinical stage so far. Currently, all studies of MSN are in preclinical stages of development. Despite the enormous potential of MSN, there are still many challenges to overcome for the use of MSN as delivery vehicles. According to the U.S. Department of Health and Human Services (2015), one of these challenges is associated with the modulation of MSN size, shape, pore size and surface chemistry, and the determination of their influence in biodistribution, toxicity and drug release. Access to targets and diffusion kinetics and, therefore, efficiency of the drug carrier, are related directly with MSN morphology and size particle distribution, which must be precisely controlled to allow a proper release (Crommelin and Florence 2013). Particle shape is one of the most important aspects in terms of cellular internalization (Vallet-Regi and Arcos Navarrete 2016; Slowing et al. 2008), and it has been also recognized that even length and curvature of nanopores may affect load capacity and drug release profiles (Sun et al. 2015). Therefore, precise modulation of shape and size are of great importance for the design of safe and efficient drug delivery systems (Mamaeva et al. 2013).

Although precise control to obtain spherical MCM-41 monodispersed nanoparticles has been already claimed in some reports (Barrabino 2011; Chen et al. 2012; Lv et al. 2016; Wanyika et al. 2011), reproducibility of results and comparison of product characteristics may be considered a critical factor of study. MSN synthesis is still far from being completely understood, since there are so many variables that must be taken into account, not all of them have been carefully studied, and some of them are often omitted. Besides, there is no agreement on the optimal conditions to achieve a specific morphology. For example, some studies have analyzed systematically the influence of variables affecting MCM-41 morphology, such as: alkoxysilane precursor (Huh et al. 2003), surfactant type (Ikari et al. 2006; Morishige et al. 1997) and surfactant concentration (Cai et al. 2001; Lelong et al. 2008; Shi et al. 2010), molar ratio of 
reactants (Bastos et al 2011; Cai et al. 2001; Manzano et al. 2008; Wanyika et al. 2011), temperature and catalyst concentration (Chen et al. 2012), and other synthesis procedures (Guo et al. 2013; Qu et al. 2006). But particularly, there are three variables of utmost importance that are not usually reported. First, stirring rate is almost always mentioned as being continuous or vigorous, but quantitative values used are not disclosed, as it is shown in our previous review (Beltrán-Osuna and Perilla 2016). Two reports were found that actually studied its influence on reaction. One of them indicates that particle size diminished from 111 to $38 \mathrm{~nm}$ when stirring speed was varied between 100 and $1000 \mathrm{rpm}$, but for MSN where the desired hexagonal arrangement of mesopores was lost (Lv et al. 2016). For MCM-41, only one study shows qualitatively that particle size distribution narrowed when stirring rate was increased (from 200 to $500 \mathrm{rpm}$ ), without further implications. Clearly, the strength of agitation should be enough to facilitate TEOS solubilization (mostly at the beginning of the reaction) and to promote the transport of reactants throughout the mesoporous structure formation. At the same time, mixing speed should not be too high to avoid a big vortex that would allow the formation of eddies in a turbulent flow. Therefore, it may be anticipated that stirring rate will affect not only size but also shape of nanoparticles. In the second place, the volume of reactants is sometimes replaced by the molar ratios between them, but reaction scale is rarely mentioned, and its influence on particle size and morphology has not been analyzed. It would not be surprising that the total volume as well as the reactor geometry influence the flow patterns in the medium, affecting the MSN shape at the mesoscopic scale. Finally and foremost, system configuration (i.e. an opened or a closed reactor) is never specified. Certainly, allowing evaporation of ethanol and water will change TEOS hydrolysis and condensation kinetics, molar ratios between reagents, and the rate of evaporation would affect the final size and shape of the particles. Knowingly or not, all these variables are commonly fixed by researchers in order to achieve the desired repeatability, but truly reproducibility is not easy to achieve due to the lack of detailed information in literature. Finally, it is worth to mention that only a scarce number of companies in the world supply this product, and there are many efforts focused in the comprehension of MSN synthesis to be indeed able to tailor MCM-41 characteristics according to final use. 
This work aims to study in detail the influence of such variables in the final nanoparticle morphology, specifically for MCM-41, since optimum conditions must differ between other types of MSN (MCM-48, SBA-15, KIT-6, etc.). To the best of our knowledge, these physical variables have not been explicitly reported; expressly the influence of the solvent evaporation rate on MSN morphology, and their influence seem absent in specialized MSN reviews (Bharti et al. 2015; Wu et al. 2013). Thus, all variables must be taken into account and reported, to completely control the MSN shape, size and size distribution. This will also allow proficiently assessing and comparing their final characteristics among different protocols and products in literature. The goal is to obtain well-shaped spherical particles in the nanometric scale $($ e.g. $100 \mathrm{~nm})$ with narrow particle size distribution, to achieve a repeatable and reproducible method to produce MSN type MCM-41.

\section{Experimental}

\section{MSN synthesis}

TEOS (99\%), hexadecyltrimethylammonium bromide (CTAB, 98\%) and sodium hydroxide $(\mathrm{NaOH})$ were employed as silica precursor, surfactant template, and catalyst, respectively. Distilled water was used in all experiments. All reagents were purchased from Sigma-Aldrich Co. and they were used as provided. In all cases, MSN synthesis was carried out in a cylindrical glass reactor. In a typical procedure (i.e. for a volume reaction of $500 \mathrm{~mL}$ ), $1 \mathrm{~g} \mathrm{CTAB}$ was added to $480 \mathrm{~mL}$ water at $30^{\circ} \mathrm{C}$, and mixed at 150 $\mathrm{rpm}$, avoiding the formation of any kind of foam. After complete dissolution, $3.5 \mathrm{~mL}$ $\mathrm{NaOH}$ aqueous solution $(2 \mathrm{M})$ was added to the homogeneous solution, the reaction temperature was raised until $80^{\circ} \mathrm{C}$ and waited for its stabilization. Then, stirring speed was increased up to $500 \mathrm{rpm}$ and the reaction started immediately when $5 \mathrm{~mL}$ of TEOS were added dropwise (at a rate of $1 \mathrm{~mL} \mathrm{~min}^{-1}$ ). Reaction time varied between 2 and 4 hours, depending on the chosen system configuration. Once the reaction had finished, the temperature of the medium was quickly decreased to $20^{\circ} \mathrm{C}$ using an ice-water bath. 
Several wash-centrifugation cycles (5000 rpm, $10 \mathrm{~min}$ ) were done until water reached a neutral $\mathrm{pH}$ and then, MSN were collected. The white precipitate was dried in oven at $80^{\circ} \mathrm{C}$ for 8 hours, and grounded in a ceramic mortar to reduce the size of the agglomerate and to homogenize the sample. To remove the surfactant from the mesoporous structure, a calcination process was used, going from room temperature to $723 \mathrm{~K}\left(10^{\circ} \mathrm{C} \mathrm{min}^{-1}\right)$, holding it up for 6 hours, and stopping the heating afterwards (the sample was removed from oven after cooling). The obtained product was a fine white powder that was kept at room conditions until characterization.

\section{Characterization}

The morphology of the calcinated MSN samples was observed via Field Emission Scanning Electron Microscopy (FESEM), using a Zeiss Oxford Instruments Ultra 55 electron microscope coupled with an in-lens detector. The mesostructure of the product was observed through Transmission Electron Microscopy (TEM) using a JEM $2100 \mathrm{f}$ electron microscope with an accelerating voltage of $200 \mathrm{kV}$. Sample preparation included sonication of 0.1-1.0 mg MSN in $1 \mathrm{~mL}$ of pure ethanol for 15 minutes. A drop of $5 \mu \mathrm{L}$ of this dispersion was directly placed on the nickel grid for TEM and on the aluminum tip for FESEM, and left to dry under room conditions. FESEM samples were gold-palladium plated before taking the micrographs. The mesoporous structure was characterized by Small-Angle X-Ray Diffraction (SAXRD), using a Bruker Axs D8 Advance Diffractometer, with $\mathrm{Cu}-\mathrm{K} \alpha$ radiation $(33 \mathrm{~kW}, 50 \mathrm{~mA}, 0.154085 \mathrm{~nm})$, a step size of $0.04^{\circ}$ and a scanning rate of 3 s by step, over the range $0.73^{\circ}<2 \theta<10^{\circ}$. MSN porosity was characterized by carrying out nitrogen adsorption/desorption isotherm measurements on a Micromeritics TriStarII PLUS analyzer at 77 K. Each sample was outgassed at $473 \mathrm{~K}$ for 10 hours before measurement. The specific surface area was calculated by the Brunauer-Emmett-Teller (BET) method and the average pore size was calculated by using Barrett-Joyner-Halenda $(\mathrm{BJH})$ model. Thermogravimetric analysis (TGA) was carried on MSN materials using a Mettler Toledo TGA/DSC, following a three-step method: a) fast heating from $30^{\circ} \mathrm{C}$ to $100^{\circ} \mathrm{C}$, b) isothermal at $100^{\circ} \mathrm{C}$ for one hour, and c) heating to $800^{\circ} \mathrm{C}$ at $10^{\circ} \mathrm{C} / \mathrm{min}$. 
Hydrodynamic particle diameter $\left(\mathrm{d}_{\mathrm{h}}\right)$ and size distribution of MSN were measured by Dynamic Light Scattering (DLS), using Malvern ZetaSizer Nano ZS ('red' laser, 632.8 $\left.\mathrm{nm}, 4 \mathrm{~mW}, 175^{\circ}\right)$. Sample dispersions were made at very low concentrations $(<0.1 \mathrm{mg}$ $\left.\mathrm{mL}^{-1}\right)$ to assure Brownian motion. Dispersions were mixed in a sonication bath for 30 minutes before each experiment. Five measurements at $20^{\circ} \mathrm{C}$ were carried out for each sample, using water and ethanol as solvents. Nanoparticle size and size distributions of the samples were also calculated by measuring the particle diameter on the micrographs, using the software Image $\mathbf{J}$ for a counting of at least 500 particles for each reported value. Average diameter of the particle $\left(d_{p}\right)$ and circularity $(C)$ were measured by Image $J$. For the non-spherical particles, $d_{p}$ was calculated as the arithmetic mean between the shortest and largest diameter observed in the micrographs. Circularity indicates how close the particle shape projection is to that of a perfect circle (for which $\mathrm{C}=1$ ). It is defined by Equation (1):

$$
C=4 A / \pi \mathrm{L}^{2}
$$

where $\mathrm{A}$ is the area of each particle on the micrograph, and L the length of the particle (Merkus 2009). In this study, L was replaced by $L_{F}$, known as the Feret diameter, which is the distance between two parallel tangents on opposite sides of the particle profile. All particles were measured in the same direction (regardless of particle orientation) to ensure statistical significance. Histograms of particle size distributions and Gaussian fitting for all samples are presented in supplementary material.

\section{Results and Discussion}

Four experimental variables, at three level each one, were analyzed during MSN synthesis: stirring speed, reaction volume, system configuration and $\mathrm{NaOH} / \mathrm{TEOS}$ molar ratio. The influence of each physicochemical variable on MSN shape was quantitatively analyzed by two means $\left(\mathrm{d}_{\mathrm{p}}\right.$ and $\left.\mathrm{C}\right)$. The product displaying the best spherical 
morphology under the electronic microscope was finally chosen and fully characterized.

\section{Influence of the stirring speed}

First, volume reaction was kept at $50 \mathrm{~mL}$, using a closed system and maintaining the same molar ratios of reactants as detailed before in the experimental section (for 500 $\mathrm{mL}$ ). A reaction time of 4 hours was established from a previous follow-up (not shown) where small samples were taken every 30 minutes from the reactor. It was concluded that shorter times do not allow a complete formation of the expected MSN morphology. In this first set of experiments, different MSN products were obtained by varying the magnetic stirring speed of the reaction at 250, 500 and $700 \mathrm{rpm}$. Since sonication is a well-established method in the synthesis of nanoparticles, an additional experiment was carried out. The reactor was placed inside a sonication bath during the whole reaction to evaluate its influence in the final state of particle aggregation. MSN morphologies found by FESEM for these four experiments are shown in Figure 1. It can be seen that at low speed rates $(250 \mathrm{rpm}$, Figure 1a) shapeless particles $(C=0.72 \pm 0.18)$ with very dispersed diameters reaching the micrometric scale $\left(d_{p}=267 \pm 131 \mathrm{~nm}\right)$ were obtained. Both, circularity and particle size were improved $\left(C=0.82 \pm 0.26\right.$ and $\left.d_{p}=184 \pm 64 \mathrm{~nm}\right)$ when the stirring speed was increased (500 rpm, Figure 1b). But, although particle size dropped significantly $\left(d_{p}=141 \pm 35 \mathrm{~nm}\right)$ for the highest stirring rate $(750 \mathrm{rpm}$, Figure 1c), bean-shaped particles were still obtained $(C=0.83 \pm 0.17)$. Well-shaped spherical nanoparticles at this scale were only achieved when sonication was used with the aim of helping MSN dispersion (Figure 1d). However, the mesoporous structure was clearly affected in that case. As shown in Figure 2, the parallel channels observed for MCM-41 when magnetic stirring was used (Figure 2a), appeared widely disordered with sonication (Figure 2b), probably due to the high energy exert during the cavitation phenomenon. Since the smallest particles were obtained at the highest speed, a value of $750 \mathrm{rpm}$ was chosen for the next stage.

\section{Influence of the reaction volume}

Reaction volume was varied in 50, 250 and $500 \mathrm{~mL}$, for a 4 hours synthesis, and its 
influence on MSN morphology is shown in Figure 3. It is seen that shape and size were improved when scaling the reaction from $50 \mathrm{~mL}\left(\mathrm{C}=0.81 \pm 0.21, \mathrm{~d}_{\mathrm{p}}=148 \pm 47 \mathrm{~nm}\right.$, Figure $3 \mathrm{a})$, to $250 \mathrm{~mL}\left(\mathrm{C}=0.87 \pm 0.21, \mathrm{~d}_{\mathrm{p}}=106 \pm 39 \mathrm{~nm}\right.$, Figure $\left.3 \mathrm{~b}\right)$. For $500 \mathrm{~mL}$, more rounded particles with less size dispersion were obtained $\left(C=0.90 \pm 0.13, d_{p}=89\right.$ $\pm 18 \mathrm{~nm}$, Figure $3 \mathrm{c}$ ). These results were attributed to the different pattern flows achieved in each scale. Indeed, previous experiments (data not shown) indicated that not only the geometry of the reactor, but even the size of the magnetic stir bar exert a significant influence on the final MSN morphology. It is worth to notice then, that results shown in Figure 3 were obtained using cylindrical glass reactors of different sizes but preserving the same height-to-diameter ratio $(\mathrm{HDR}=1.2)$. The length of the magnetic bars was varied to keep a constant relation between both, the stir bar and reactor diameter. Although spherical shaped particles were obtained for the highest tested dilution $(500 \mathrm{~mL})$, Figure $3 \mathrm{c}$ shows some other nanoparticles $\left(\mathrm{d}_{\mathrm{p}}<20 \mathrm{~nm}\right.$, not considered for $\mathrm{C}$ and $\mathrm{d}_{\mathrm{p}}$ values previously reported) suggesting a possible Ostwald ripening. This could have been originated because of excessive stirring, leading to a turbulent flow where small particles are prone to be formed. Therefore, a feedback experimental set was carried out to test three new levels of the stirring speed at a reaction volume of $500 \mathrm{~mL}$, as shown in Figure 4. It is seen that a value of $375 \mathrm{rpm}$ (Figure 4a) is not high enough to obtain a homogeneous spherical shape, as it was better achieved at 500 or $650 \mathrm{rpm}$ (Figures $4 \mathrm{~b}$ and $4 \mathrm{c}$ ). The effect of stirring rate on $\mathrm{C}$ and $\mathrm{d}_{\mathrm{p}}$ is shown in Figure 5, where the highest value of circularity is reached for the highest stirring speed. However, it is obtained at the expense of broadening the particle size distribution, as seen in the error bars. Therefore, considering the closer values for $\mathrm{C}$ and $d_{p}$ between the last two stirring rates values, $500 \mathrm{~mL}$ and $500 \mathrm{rpm}$ were the conditions selected for the next stage.

\section{Influence of the system configuration}

Until here, all experiments have been carried out in a closed system (where loss of mass toward the atmosphere was not possible). Two more experiments were made, now in an opened system (allowing complete release of the evaporated solvent) and a partially 
opened system (restricting a percentage of the opening area). In both cases, reaction time was reduced to 2 hours, because solvent evaporation diminished the reaction volume to $1 / 4$ and $1 / 2$ of the initial value for the opened and partially opened systems, respectively. It may be observed that when no restriction was placed on the opening exit (with an area of $64 \mathrm{~cm}^{2}$ ), not only particle size increased drastically from $\mathrm{d}_{\mathrm{p}}=111 \pm 13$ $\mathrm{nm}\left(500 \mathrm{rpm}\right.$, Figure 5) to $\mathrm{d}_{\mathrm{p}}=406 \pm 89 \mathrm{~nm}$ (Figure $6 \mathrm{a}$ ) but also angular profiles were developed at the mesoscopic scale, reshaping the MSN surface $(C=0.75 \pm 0.27)$. These changes were probably due to the loss of the ethanol evaporated during the reaction, displacing the TEOS hydrolysis equilibrium and gradually changing the polarity of the medium. In this way, more TEOS was hydrolyzed but became less soluble, modifying the mesoporous structure evolution compared to the closed system. The hydrolyzed TEOS polymerized preferably on the surface of already formed MSN, in order to minimize surface energy. Thus, less particles, but with larger sizes, were formed. Then, CTAB and TEOS interactions forming the mesoporous template were also affected by different transport phenomena, such as ethanol diffusion gradient, along with convection and flow patterns. As a result of this very complex dynamic phase behavior, edges on the MSN surfaces were formed. Since dilution plays a fundamental role in phase behavior, further experiments would be required to gather information about a possible formation of a lamellar phase of the surfactant. This might be influencing the mesostructure evolution of the particle and, therefore, the appearance of edges on the final MSN morphology. From these results, it is concluded that a partially opened system (i.e. covering 4/5 of the opening area) becomes the most adequate alternative, producing particles with remarkable spherical shape and nanometric size $(\mathrm{C}=0.97 \pm$ $0.09, d_{p}=95 \pm 15 \mathrm{~nm}$ ) as shown in Figure 6b. Clearly, ethanol evaporation rate is in this way set to a proper value where it enhances TEOS hydrolysis, while allowing the formation of well-shaped and monodispersed nanoparticles in a proper diluted medium. This result was obtained using a $\mathrm{NaOH} / \mathrm{TEOS}$ molar ratio of 0.3 . The influence of this value was also studied and presented as follows. 


\section{Influence of the NaOH/TEOS molar ratio}

The $\mathrm{NaOH} / \mathrm{TEOS}$ molar ratio was varied in three levels $(0.03,0.3$ and 0.5$)$ for a partially opened system, to study the influence of the catalyst on MSN morphology. It was observed that nanoparticle size was directly dependent on catalyst concentration. The size doubled from $40 \pm 5 \mathrm{~nm}$ (Figure 7a) to $95 \pm 15 \mathrm{~nm}$ (Figure 7b, same sample shown in Figure 6b), when $\mathrm{NaOH} / \mathrm{TEOS}$ molar ratio was 10 times increased. However, when this value was increased from 0.3 to 0.5 (Figure $7 \mathrm{c}$ ), a non-proportional trend was observed with final particle sizes reaching almost half micron $\left(d_{p}=480 \pm 112 \mathrm{~nm}\right)$. Besides these widely dispersed sizes, the appearance of edged morphologies $(C=0.79 \pm$ 0.11) was also evident. $\mathrm{NaOH} / \mathrm{TEOS}$ molar ratios values were chosen based on the study of Chen and coworkers (Chen et al. 2012), which reports a perfect linear relationship between particle diameters $(40 \pm 4,80 \pm 7,120 \pm 13$, and $160 \pm 20 \mathrm{~nm})$ and $\mathrm{NaOH} / \mathrm{TEOS}$ molar ratios $(0.2,0.3,0.4$ and 0.5$)$. The authors claimed the complete and precise control for nanosized MCM-41 and selected 200-300 rpm as the best stirring speed. However, equally important variables were not mentioned, such as system configuration, reactor geometry or TEOS addition rate that could lead to the reproducibility and fair comparison among literature results.

\section{Physicochemical characterization of MCM-41}

In order to corroborate the nature of the MCM-41 material, the sample with better circularity (Figures $6 \mathrm{~b}$ and $7 \mathrm{~b}$ ) was fully characterized. First, $\mathrm{N}_{2}$ adsorption-desorption isotherm measurements (Figure 8) show an isotherm type IV according to the IUPAC classification (IUPAC 1985). Four zones are observed: (i) a linear region at a low relative pressure, $P / P_{0}$, where BET model was applied (assigned to the formation of a $\mathrm{N}_{2}$ adsorbed monolayer), (ii) an increase step at a medium relative pressure $\left(P / P_{0}=0.2\right.$ 0.4) due to capillary condensation, (iii) a long plateau, and (iv) a final increase at a high relative pressure $\left(P / P_{0}>0.8\right)$ corresponding to the filling of voids among particles. An important disagreement among literature is related with the appearance of a hysteresis loop between adsorption and desorption curves. Many authors attribute this loop as a proof of the existence of mesoporosity for MCM-41 (Ukmar et al. 2011; Zhou et al. 
2016), while others reports indicate that it is actually the absence of hysteresis, which suggests the formation of uniform cylindrical mesopores inside the nanoparticle (Bernardos et al. 2010; Khezri et at. 2014). Original IUPAC classification describes indeed the existence of a hysteresis loop in the definition of a type IV curve. But although currently applied by many, it has to be noticed that this classification is dated from more than three decades ago, when MCM-41 materials were not yet on scene (firstly reported in 1992 by Beck et al. (1992) and Kresge et al. (1992)). Indeed, current studies have demonstrated that the same MCM-41 material may exhibit nearly reversible isotherms or well-defined hysteresis loops, depending on test operational conditions such as temperature (Rouquerol et al. 2014), pore size distribution or the nature of the gas adsorbed (Selvam et al. 2001). In this study, the corresponding total surface area $\left(\mathrm{A}_{\mathrm{s}}\right)$, average pore diameter $\left(\phi_{\text {pore }}\right)$ and pore volume $\left(v_{\text {pore }}\right)$ were obtained using BET and BJH models, and the results are summarized in Table 1. A very narrow pore size distribution (as shown in insert Figure 8) was also observed, indicating a homogeneous mesoporous structure inside the MSN product.

Although silicon dioxide is an amorphous material, mesoporous inside MSN may be analyzed as if they were organized in a unit cell and measured by SAXRD, as shown in Figure 9a. Three well resolved peaks were found: one sharp and intense peak around $2 \theta$ from $2.0^{\circ}$ to $2.5^{\circ}$, and two other less intense peaks between $2 \theta$ from $3.5^{\circ}$ to $5.0^{\circ}$, as expected for MCM-41 (Khezri et at. 2014). The main peak $\left(2 \theta=2.128^{\circ}\right)$ is shifted around $2 \theta=0.16^{\circ}$ for the calcinated sample, which corresponds to the contraction of the unitary cell (due to silanol group condensation along heat treatment). This decrease in the interplanar space is also associated to CTAB decomposition inside the pores (Shibata et al. 2010). These three well-resolved peaks shown in Figure 9a may be assigned to the reflections of (100), (110) and (200) diffraction planes for a 2-D hexagonal lattice $\left(p 6 \mathrm{~mm}\right.$ ). From the principal interplanar spacing, $d_{(100)}=38,605 \AA$ (obtained from Bragg's law), the lattice parameter for the hexagonal arrangements of MCM-41 was calculated as a $0=2 d_{(100)} / \sqrt{ } 3=44,6 \AA$. Wall thickness (w) was also estimated from pore diameter $\left(\phi_{\text {pore }}=2.8 \mathrm{~nm}\right.$, obtained by BJH model $)$ as: $\mathrm{w}=\mathrm{a}_{0}-\phi_{\text {pore }}$ 
$=16.6 \AA$, which falls within the expected values, between $10-27 \AA$ for a calcinated silica type MCM-41 (Edler 1997).

Hexagonal arrangements were also clearly verified by TEM images (Figure 9b), and MCM-41 pore measurements by ImageJ software gave as result an average value of $\phi_{\text {pore }}=2.7 \mathrm{~nm}$, which is in excellent agreement with the average pore diameter obtained from SAXRD patterns and adsorption isotherms. Also, it must be noticed that heat treatment has a big influence on the structure of mesoporous materials, which are conventionally calcinated at $823 \mathrm{~K}$ (Beltrán-Osuna and Perilla 2016). However, this temperature could be excessive, since complete removal of CTAB from pores has been proven to take place at $613 \mathrm{~K}$, and sintering of silica walls occurs at temperatures higher than $823 \mathrm{~K}$ (Shibata et al. 2010). This phenomenon could reinforce the mechanical properties of the material, but diminishing the pore volume, which is not desired if MSN are used as delivery vehicles. For this reason, an intermediate temperature (723 K) was used in this study, and it was proved that the hexagonal mesoporous structure was always conserved. Also, CTAB removal from pores was verified by thermogravimetric analysis, since a small weight loss $(<2 \%)$ was calculated for the calcinated sample (see Supplementary material). This drop was expected due to the loss of water of hydration at high temperatures (Iliade et al. 2012).

Finally, $\mathrm{d}_{\mathrm{h}}$ of MSN (dispersed in water and ethanol) was obtained by DLS technique, and the results are shown in Figure 10. Larger particles were detected using water as a solvent $\left(\mathrm{d}_{\mathrm{h}}=201.4 \mathrm{~nm} \pm 44 \mathrm{~nm}\right)$ suggesting particle agglomeration. Instead, the lower sizes were measured when using ethanol $\left(d_{h}=115.5 \mathrm{~nm} \pm 10 \mathrm{~nm}\right)$ since a less polar medium allows disruption of particle association due to hydroxyl groups left on MSN surface. Only one peak was obtained in both cases, showing good repeatability. These results are in agreement with particle size measured on FESEM images by the ImageJ software ( $d_{p}=95 \pm 15 \mathrm{~nm}$, Figure $\left.6 b\right)$, taking into account that $d_{h}$ values are always higher than $d_{p}$ because of particle solvation and other hydrodynamic effects. All the results are summarized in Table 1. According with their size, pore diameter and pore 
morphology, the MSN synthesized could be used in several biomedical applications, especially for the design of drug delivery systems.

\section{Conclusions}

Well-shaped spherical mesoporous silica nanoparticles were obtained, with particle size of $95 \mathrm{~nm}$ and pore size of $2.8 \mathrm{~nm}$. The high degree of order in the mesopores arrangement expected for a type MCM-41 silica material was corroborated by SAXRD and a total surface area of $954 \mathrm{~m}^{2} \mathrm{~g}^{-1}$ and a volume pore of $0.66 \mathrm{~cm}^{3} \mathrm{~g}^{-1}$ were calculated from nitrogen adsorption-desorption isotherms. Physical parameters such as stirring speed, reactor geometry, reaction scale and system configuration were proved to have a significant influence on final MSN morphology. It is concluded that transport phenomena associated with flow patterns, convection and diffusion gradients, along with a complex phase behavior, control the final particle shape at the mesoscopic scale. Almost perfect spherical morphology with low size dispersity was only obtained for a partially open system, for which a moderate ethanol evaporation rate promotes TEOS hydrolysis, but allowing particle formation at an appropriate dilution. Catalyst concentration was found to be the principal variable affecting particle size, following a direct but not proportional relationship between particle diameter and $\mathrm{NaOH}$ /TEOS molar ratio. Clearly, a complete report of all reaction conditions is essential in literature to achieve the desired repeatability and reproducibility on MSN synthesis.

\section{Acknowledgements}

José L. Gómez Ribelles acknowledges the support of the Ministerio de Economía y Competitividad, MINECO (research number MAT2016-76039-C4-1-R). CIBER-BBN is an initiative funded by the VI National R\&D\&i Plan 2008-2011, Iniciativa Ingenio 2010, Consolider Program, CIBER Actions and financed by the Instituto de Salud Carlos III with assistance from the European Regional Development Fund. This work was also supported by COLCIENCIAS (Departamento Administrativo de Ciencia Tecnología e Innovación, Convocatoria 567 Doctorados Nacionales) and Universidad 
Nacional de Colombia (grant number DIB 201010021438).

The authors would like to thank Professor Ramón Martínez Máñez, Scientific Director of CIBER's Bioengineering, Biomaterials and Nanomedicine (CIBER-BBN), and his research group at the Laboratory of Nanomedicine, from the Center for Molecular Recognition and Technological Development (UPV-IQMA), for their support and willingness. The authors acknowledge the assistance from the Microscopy Service at the UPV where all micrographs were taken.

\section{Compliance with Ethical Standards}

Funding: This study was funded partially by Departamento Administrativo de Ciencia Tecnología e Innovación - COLCIENCIAS (Recipient, Angela A. Beltrán-Osuna); Ministerio de Economía y Competitividad, MINECO, research number MAT2016-76039-C4-1-R (Recipient, José L. Gómez-Ribelles); and Universidad Nacional de Colombia, grant number DIB 201010021438 (Recipient, Jairo E. Perilla)

Conflict of Interest: The authors declare that they have no conflict of interest.

\section{Reference list}

Barrabino A (2011) Synthesis of mesoporous silica particles with control of both pore diameter and particle size. Master Thesis, Chalmers University of Technology, Sweden.

Bastos FS, Lima OA, Filho CR, Fernandes LD (2011) Mesoporous molecular sieve MCM-41 synthesis from fluoride media. Brazilian J Chem Eng 28:649-658.

Beck JS, Vartuli JC, Roth WJ, et al (1992) A new family of mesoporous molecular sieves prepared with liquid crystal templates. J Am Chem Soc 10834-10843. doi: 10.1021/ja00053a020

Beltrán-Osuna AA, Perilla JE (2016) Colloidal and spherical mesoporous silica particles: synthesis and new technologies for delivery applications. J Sol-Gel Sci Technol 77:480496. doi: 10.1007/s10971-015-3874-2

Bernardos A, Mondragón L, Aznar E, et al (2010) Enzyme-responsive intracellular 
controlled release using nanometric silica mesoporous supports capped with "saccharides." ACS Nano 4:6353-6368.

Bharti C, Nagaich U, Pal AK, Gulati N (2015) Mesoporous silica nanoparticles in target drug delivery system: a review. Int J Pharm Investig 5:124-133. doi:

10.4103/2230-973X.160844

Brevet D, Hocine O, Delalande A, et al (2014) Improved gene transfer with

histidine-functionalized mesoporous silica nanoparticles. Int J Pharm 471:197-205. doi: 10.1016/j.ijpharm.2014.05.020

Cai Q, Luo Z, Pang W, et al (2001) Dilute solution routes to various controllable morphologies of MCM-41 silica with a basic medium. Chem Mater 13:258-263.

Chakraborty I, Mascharak PK (2016) Mesoporous silica materials and nanoparticles as carriers for controlled and site-specific delivery of gaseous signaling molecules. Microporous Mesoporous Mater 234:409-419. doi: 10.1016/j.micromeso.2016.07.028

Chen L, Zhang Z, Yao X, et al (2015a) Intracellular pH-operated mechanized mesoporous silica nanoparticles as potential drug carries. Microporous Mesoporous Mater 201:169-175. doi: 10.1016/j.micromeso.2014.09.023

Chen X, Yao X, Wang C, et al (2015b) Mesoporous silica nanoparticles capped with fluorescence-conjugated cyclodextrin for $\mathrm{pH}$-activated controlled drug delivery and imaging. Microporous Mesoporous Mater 217:46-53. doi:

10.1016/j.micromeso.2015.06.012

Chen Y, Chen H, Shi J (2013) In vivo bio-safety evaluations and diagnostic / therapeutic applications of chemically designed mesoporous silica nanoparticles. Adv Mater 25:3144-3176.

Chen Y, Shi X, Han B, et al (2012) The complete control for the nanosize of spherical MCM-41. J Nanosci Nanotechnol 12:7239-49. doi: 10.1166/jnn.2012.6459

Cheng Y-J, Zeng X, Cheng D-B, et al (2016) Functional mesoporous silica nanoparticles (MSNs) for highly controllable drug release and synergistic therapy. Colloids Surfaces B Biointerfaces 145:217-225. doi: 10.1016/j.colsurfb.2016.04.051

Crommelin DJA, Florence AT (2013) Towards more effective advanced drug delivery systems. Int J Pharm 454:496-511. doi: 10.1016/j.ijpharm.2013.02.020

Edler KJ (1997) Synthesis and characterisation of the mesoporous molecular sieve, MCM-41. Doctoral dissertation, The Australian National University, Australia.

Guo Z, Liu X-M, Ma L, et al (2013) Effects of particle morphology, pore size and surface coating of mesoporous silica on naproxen dissolution rate enhancement. 
Colloids Surf B Biointerfaces 101:228-35. doi: 10.1016/j.colsurfb.2012.06.026

Han N, Wang Y, Bai J, et al (2016) Facile synthesis of the lipid bilayer coated mesoporous silica nanocomposites and their application in drug delivery. Microporous Mesoporous Mater 219:209-218. doi: 10.1016/j.micromeso.2015.08.006

Hu X, Wang Y, Peng B (2014) Chitosan-capped mesoporous silica nanoparticles as pH-responsive nanocarriers for controlled drug release. Chem - An Asian J 9:319-327. doi: 10.1002/asia.201301105

Huh S, Wiench JW, Yoo J, et al (2003) Organic functionalization and morphology control of mesoporous silicas via a co-condensation synthesis method. Chem Mater 4247-4256. doi: 10.1021/cm0210041

Ikari K, Suzuki K, Imai H (2006) Structural control of mesoporous silica nanoparticles in a binary surfactant system. Langmuir 22:802-806. doi: 10.1021/la0525527

Iliade P, Miletto I, Coluccia S, Berlier G (2012) Functionalization of mesoporous MCM-41 with aminopropyl groups by co-condensation and grafting: a physico-chemical characterization. Res Chem Intermed 38:785-794. doi: 10.1007/s11164-011-0417-5

IUPAC (1985) Reporting physisorption data for gas/solid systems. Pure Appl Chem 57:603-619.

IUPAC (2014) Compendium of Chemical Terminology - Gold Book, 2.3.3. International Union of Pure and Applied Chemistry

Khezri K, Roghani-Mamaqani H, Sarsabili M, et al (2014) Spherical mesoporous silica nanoparticles/tailor-made polystyrene nanocomposites by in situ reverse atom transfer radical polymerization. Polym Sci Ser B 56:909-918. doi:

$10.1134 / \mathrm{S} 1560090414660026$

Kresge CT, Leonowicz ME, Roth WJ, et al (1992) Ordered mesoporous molecular sieves synthesized by a liquid-crystal template mechanism. Nature 359:710-712. doi: $10.1038 / 359710 \mathrm{a} 0$

Lelong G, Bhattacharyya S, Kline S, et al (2008) Effect of surfactant concentration on the morphology and texture of MCM-41 materials. J Phys Chem C 112:10674-10680. doi: $10.1021 / j p 800898 \mathrm{n}$

Lv X, Zhang L, Xing F, Lin H (2016) Controlled synthesis of monodispersed mesoporous silica nanoparticles: particle size tuning and formation mechanism investigation. Microporous Mesoporous Mater 225:238-244. doi: 10.1016/j.micromeso.2015.12.024 
Mamaeva V, Sahlgren C, Lindén M (2013) Mesoporous silica nanoparticles in medicine: recent advances. Adv Drug Deliv Rev 65:689-702. doi: 10.1016/j.addr.2012.07.018

Manzano M, Aina V, Areán CO, et al (2008) Studies on MCM-41 mesoporous silica for drug delivery: effect of particle morphology and amine functionalization. Chem Eng J 137:30-37. doi: 10.1016/j.cej.2007.07.078

Merkus HG (2009) Particle size measurements: fundamentals, practice, quality. Springer Science +Businees Media B.V., The Netherlands.

Morishige K, Fujii H, Uga M, Kinukawa D (1997) capillary critical point of argon, nitrogen, oxygen, ethylene, and carbon dioxide in MCM-41. Langmuir 13:3494-3498. doi: $10.1021 / 1 a 970079 u$

Oliveira DC de P, de Barros ALB, Belardi RM, et al (2016) Mesoporous silica nanoparticles as a potential vaccine adjuvant against Schistosoma mansoni. J Drug Deliv Sci Technol 35:234-240. doi: 10.1016/j.jddst.2016.07.002

Phillips E, Penate-Medina O, Zanzonico PB, et al (2014) Clinical translation of an ultrasmall inorganic optical-PET imaging nanoparticle probe. Sci Transl Med 6:260ra149. doi: 10.1126/scitranslmed.3009524

Qu F, Zhu G, Lin H, et al (2006) A controlled release of ibuprofen by systematically tailoring the morphology of mesoporous silica materials. J Solid State Chem 179:20272035. doi: $10.1016 /$ j.jssc.2006.04.002

Rafi AA, Mahkam M, Davaran S, Hamishehkar H (2016) A smart pH-responsive nano-carrier as a drug delivery system: a hybrid system comprised of mesoporous nanosilica MCM-41 (as a nano-container) \& a pH-sensitive polymer (as smart reversible gatekeepers): Preparation, characterization and in vitro releas. Eur J Pharm Sci 93:64-73. doi: http://dx.doi.org/10.1016/j.ejps.2016.08.005

Rouquerol J, Rouquerol F, Llewellyn P, et al (2014) Adsorption by powders and porous solids: principles, methodology and applications. Elsevier Ltd.

Selvam P, Bhatia SK, Sonwane CG (2001) Recent advances in processing and characterization of periodic mesoporous MCM-41 silicate molecular sieves. Ind Eng Chem Res 40:3237-3261. doi: 10.1021/ie0010666

Shi YT, Cheng HY, Geng Y, et al (2010) The size-controllable synthesis of nanometer-sized mesoporous silica in extremely dilute surfactant solution. Mater Chem Phys 120:193-198. doi: 10.1016/j.matchemphys.2009.10.045

Shibata H, Chiba Y, Kineri T, et al (2010) The effect of heat treatment on the interplanar spacing of the mesostructure during the synthesis of mesoporous MCM-41 silica. Colloids Surfaces A Physicochem Eng Asp 358:1-5. doi: 
Slowing II, Vivero-Escoto JL, Wu C-W, Lin VSY (2008) Mesoporous silica nanoparticles as controlled release drug delivery and gene transfection carriers. Adv Drug Deliv Rev 60:1278-1288. doi: http://dx.doi.org/10.1016/j.addr.2008.03.012

Sun R, Wang W, Wen Y, Zhang X (2015) Recent advance on mesoporous silica nanoparticles-based controlled release system: intelligent switches open up.

Nanomaterials 5:2019-2053. doi: 10.3390/nano5042019

U.S. Department of Health \& Human Services (2015) Cancer Nanotechnology Plan.

Ukmar T, Maver U, Planinšek O, et al (2011) Understanding controlled drug release from mesoporous silicates: theory and experiment. J Control Release 155:409-417. doi: 10.1016/j.jconrel.2011.06.038

Vallet-Regi M, Arcos Navarrete D (2016) Nanoceramics in Clinical Use, 1st edition. The Royal Society of Chemistry, Cambridge

Vallet-Regi M, Rámila A, Del Real RP, Pérez-Pariente J (2001) A new property of MCM-41: drug delivery system. Chem Mater 13:308-311. doi: 10.1021/cm0011559

Varga N, Benko M, Sebok D, et al (2015) Mesoporous silica core-shell composite functionalized with polyelectrolytes for drug delivery. Microporous Mesoporous Mater 213:134-141. doi: 10.1016/j.micromeso.2015.02.008

Wang Y, Zhao Q, Han N, et al (2015) Mesoporous silica nanoparticles in drug delivery and biomedical applications. Nanomedicine Nanotechnology, Biol Med 11:313-327. doi: 10.1016/j.nano.2014.09.014

Wanyika H, Gatebe E, Kioni P, et al (2011) Synthesis and characterization of ordered mesoporous silica nanoparticles with tunable physical properties by varying molar composition of reagents. African J Pharm Pharmacol 5:2402-2410. doi: 10.5897/AJPP11.592

Wu SH, Mou CY, Lin HP (2013) Synthesis of mesoporous silica nanoparticles. Chem Soc Rev 42:3862-3875. doi: 10.1039/c3cs35405a

Xu X, Lü S, Gao C, et al (2015a) Facile preparation of pH-sensitive and self-fluorescent mesoporous silica nanoparticles modified with PAMAM dendrimers for label-free imaging and drug delivery. Chem Eng J 266:171-178. doi: 10.1016/j.cej.2014.12.075

Xu X, Lü S, Gao C, et al (2015b) Polymeric micelle-coated mesop orous silica nanoparticle for enhanced fluorescent imaging and $\mathrm{pH}$-responsive drug delivery. Chem Eng J 279:851-860. doi: 10.1016/j.cej.2015.05.085 
Xu X, Lü S, Gao C, et al (2016) Self-fluorescent and stimuli-responsive mesoporous silica nanoparticles using a double-role curcumin gatekeeper for drug delivery. Chem Eng J 300:185-192. doi: 10.1016/j.cej.2016.04.087

Yang Y, Yu C (2015) Advances in silica based nanoparticles for targeted cancer therapy. Nanomedicine Nanotechnology, Biol Med 12:317-332. doi:

10.1016/j.nano.2015.10.018

Zhang H, Tong C, Sha J, et al (2015) Fluorescent mesoporous silica nanoparticles functionalized graphene oxide: a facile FRET-based ratiometric probe for $\mathrm{Hg}^{2+}$. Sensors Actuators, B Chem 206:181-189. doi: 10.1016/j.snb.2014.09.051

Zhou C, Yan C, Zhao J, et al (2016) Rapid synthesis of morphology-controlled mesoporous silica nanoparticles from silica fume. J Taiwan Inst Chem Eng 62:307-312. doi: 10.1016/j.jtice.2016.01.031 
Table 1 Characterization of MCM-41 synthesized nanoparticles

\begin{tabular}{ccl}
\hline Property & Value & Units \\
\hline Surface area, $\mathrm{A}_{\mathrm{s}}$ & 954.3 & $\mathrm{~m}^{2} \mathrm{~g}^{-1}$ \\
Pore volume, $\mathrm{v}_{\text {pore }}$ & 0.658 & $\mathrm{~cm}^{3} \mathrm{~g}^{-1}$ \\
Pore size, $\phi_{\text {pore }}$ & 2.8 & $\mathrm{~nm}$ \\
Lattice parameter, $\mathrm{a} 0$ & 44.58 & $\AA$ \\
Wall thickness, $\mathrm{w}$ & 12.08 & $\AA$ \\
Particle size, $\mathrm{d}_{\mathrm{p}}$ & 95 & $\mathrm{~nm}$ \\
Hydrodynamic diameter, $\mathrm{d}_{\mathrm{h}}$ & 115 & $\mathrm{~nm}$ \\
\hline
\end{tabular}




\section{Figure captions}

Fig. 1 MSN morphology obtained at different stirring speeds for a reaction volume of $50 \mathrm{~mL}$ : a) $250 \mathrm{rpm}$, b) $500 \mathrm{rpm}$, c) $750 \mathrm{rpm}$, d) with a sonication bath

Fig. 2 Mesoporous structure obtained using a reaction volume of $50 \mathrm{~mL}$ : a) magnetic stirring (750 rpm), b) sonication stirring

Fig. 3 MSN morphology obtained at different reaction volumes for a stirring speed of $750 \mathrm{rpm}$ : a) $50 \mathrm{~mL}$, b) $250 \mathrm{~mL}$ c) $500 \mathrm{~mL}$

Fig. 4 MSN morphology obtained at different stirring speeds for a reaction volume of $500 \mathrm{~mL}:$ a) $350 \mathrm{rpm}$, b) $500 \mathrm{rpm}$, c) $650 \mathrm{rpm}$

Fig. 5 Influence of stirring speed on circularity (C) and particle size $\left(d_{p}\right)$ for MSN (reaction volume: $500 \mathrm{~mL}$ ). Error bars represent one standard deviation

Fig. 6 MSN morphology obtained at 500 rpm using: a) a complete opened system, b) a partially opened system ( $80 \%$ of opening area covered, compared to the closed system)

Fig. 7 Influence of catalyst concentration on MSN morphology for a partially opened system, varying $\mathrm{NaOH} / \mathrm{TEOS}$ molar ratio between: a) 0.03 , b) 0.3 , c) 0.5

Fig. 8 Adsorption-desorption isotherms of nitrogen at $77 \mathrm{~K}$ for MSN type MCM-41. Insert shows sample pore size distribution obtained from BJH model

Fig. 9 Mesoporous arrangement for MCM-41: a) SAXRD measurements for native and calcinated material, b) TEM micrograph showing the hexagonal alignment of mesopores 
Fig. 10 Hydrodynamic particle measurements obtained from DLS for MSN type MCM-41 using: a) water, b) ethanol, as solvent (Measurement temperature: $20^{\circ} \mathrm{C}$ ) 


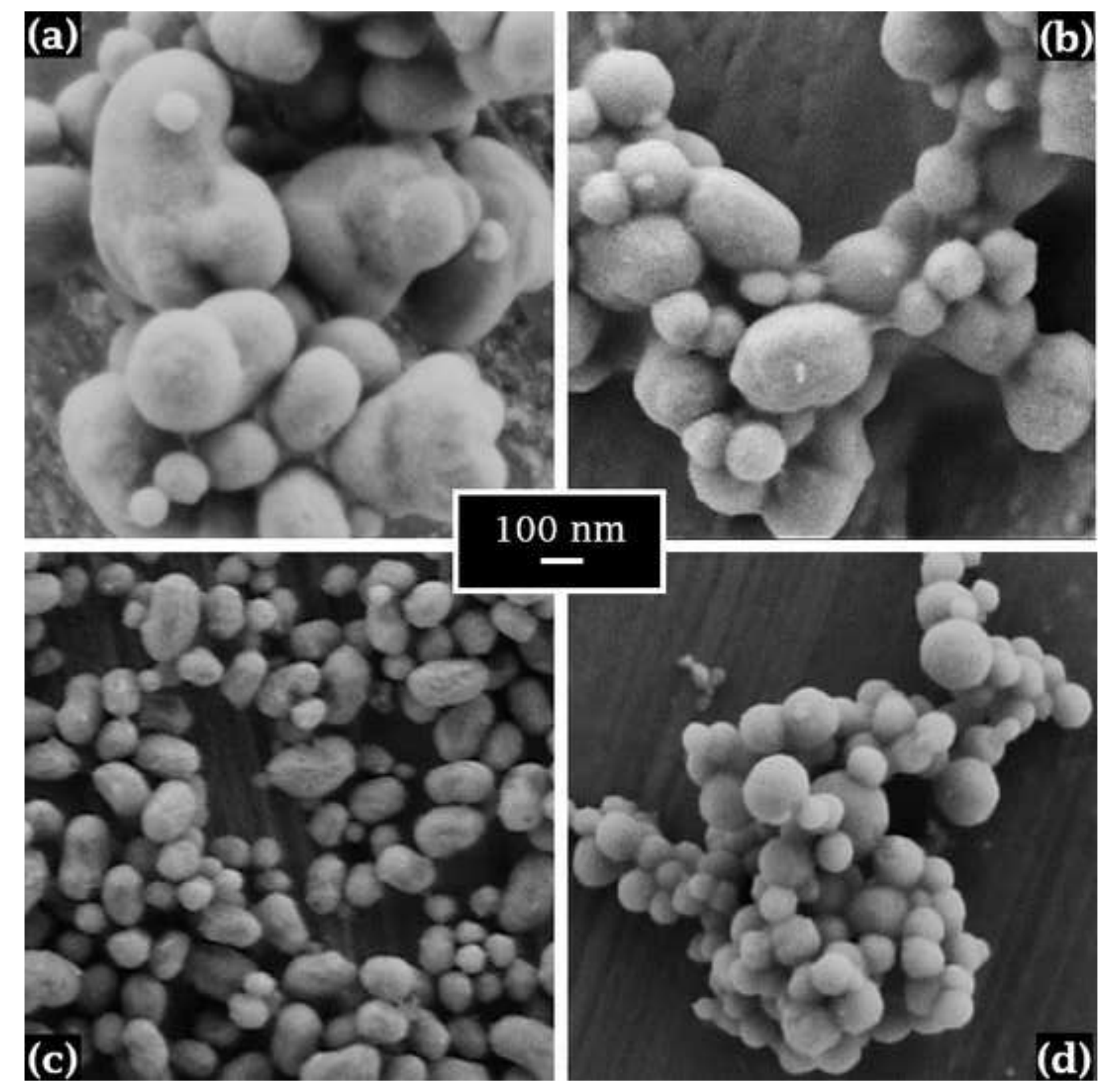




\section{(a)}
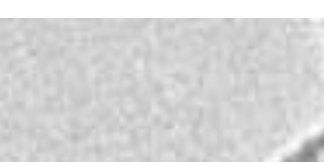
. (e)
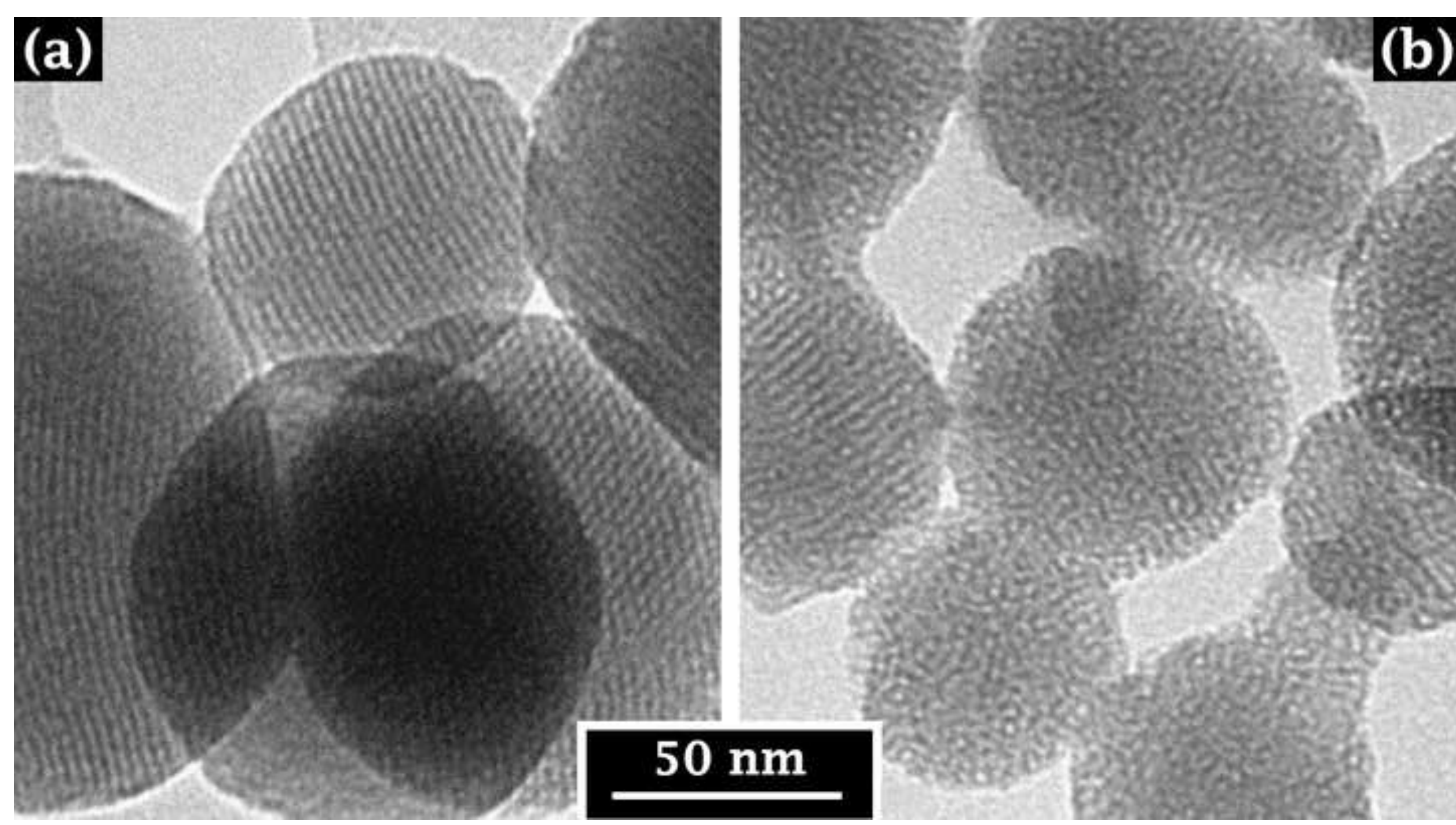

yostason

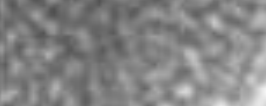

$48, y^{3}=$
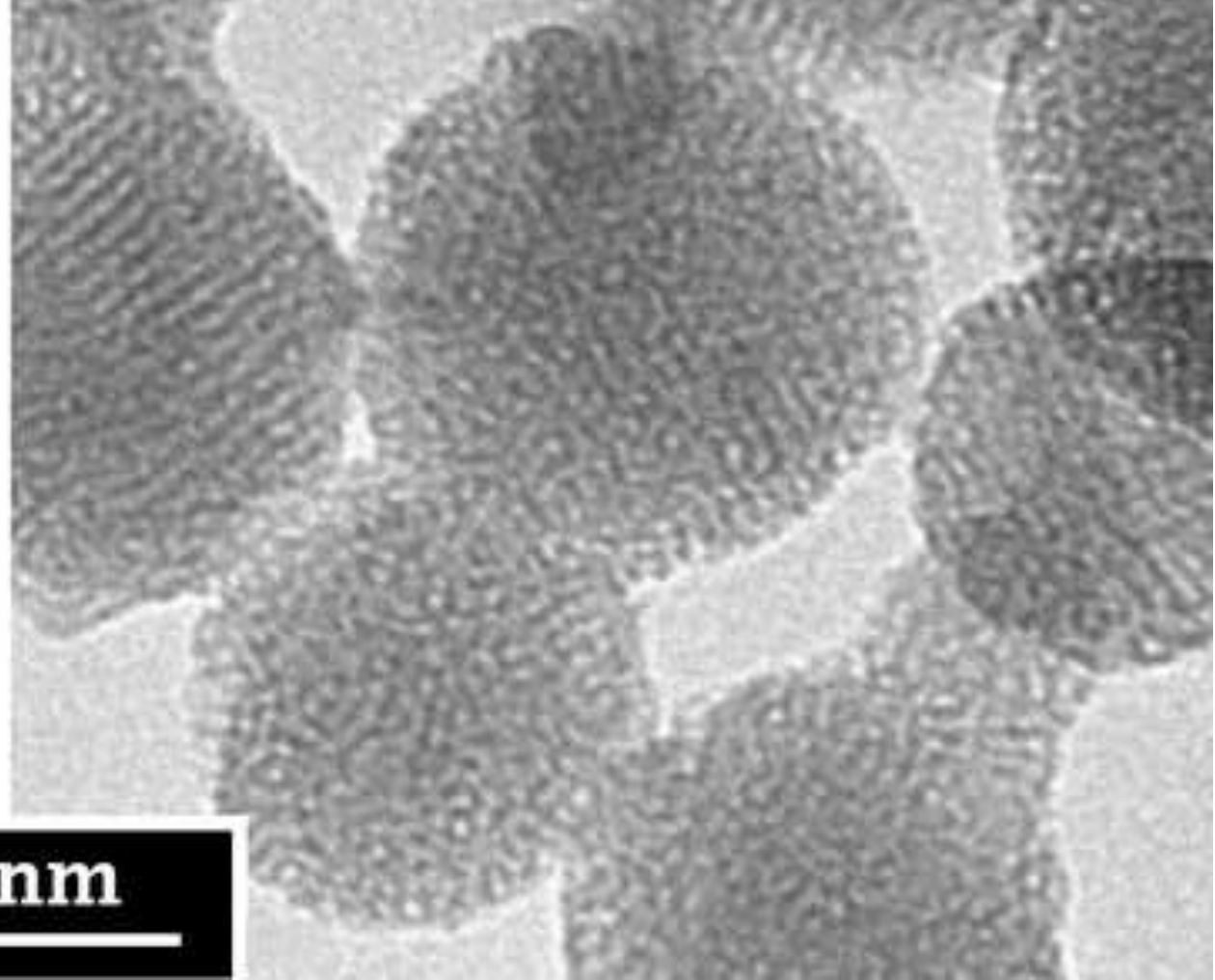

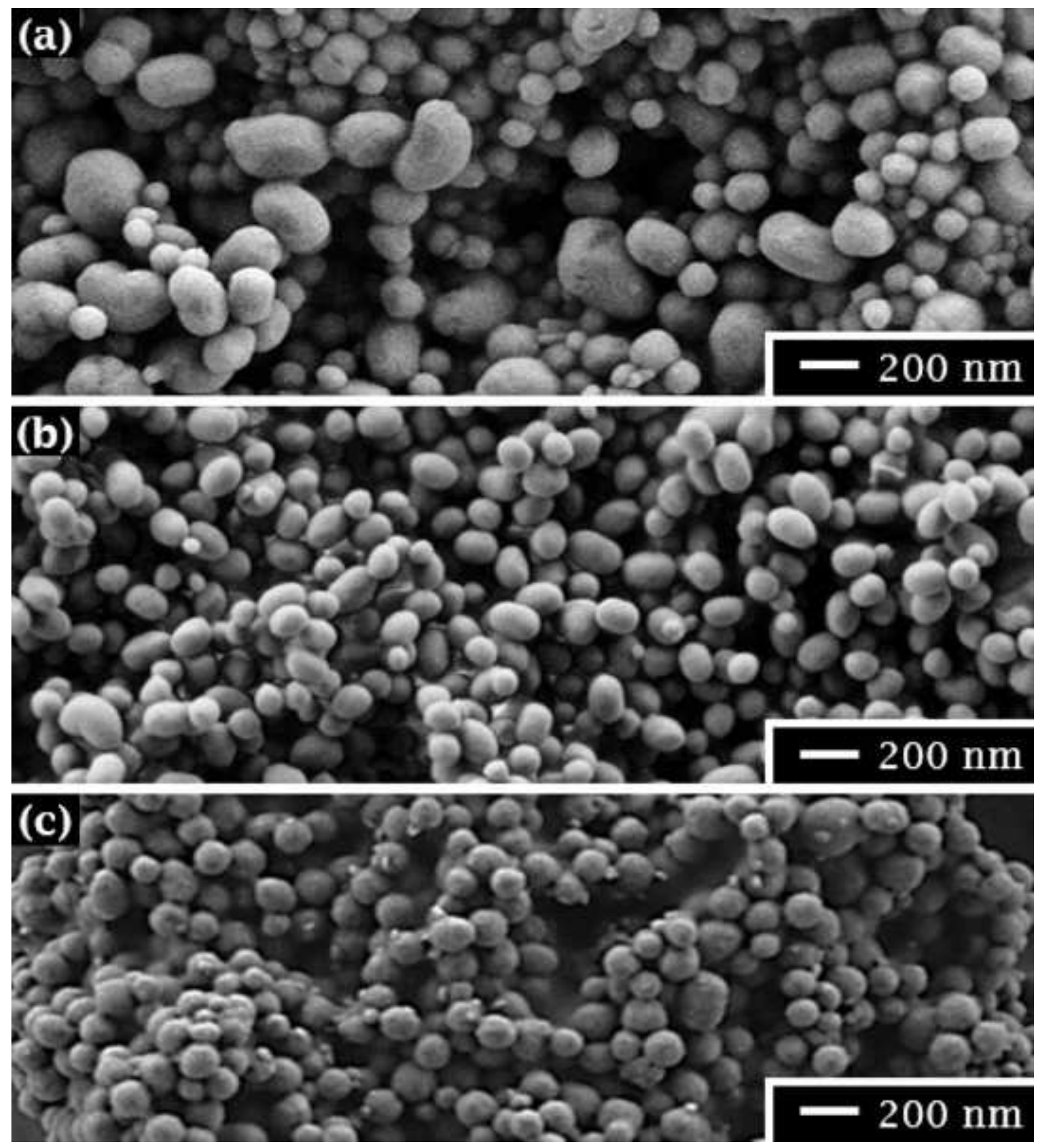

(3)
Click here to download Figure Fig 3.tiff $\stackrel{ \pm}{*}$

(a)

Fig. 3

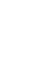

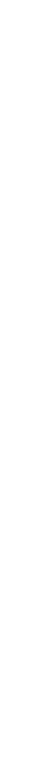




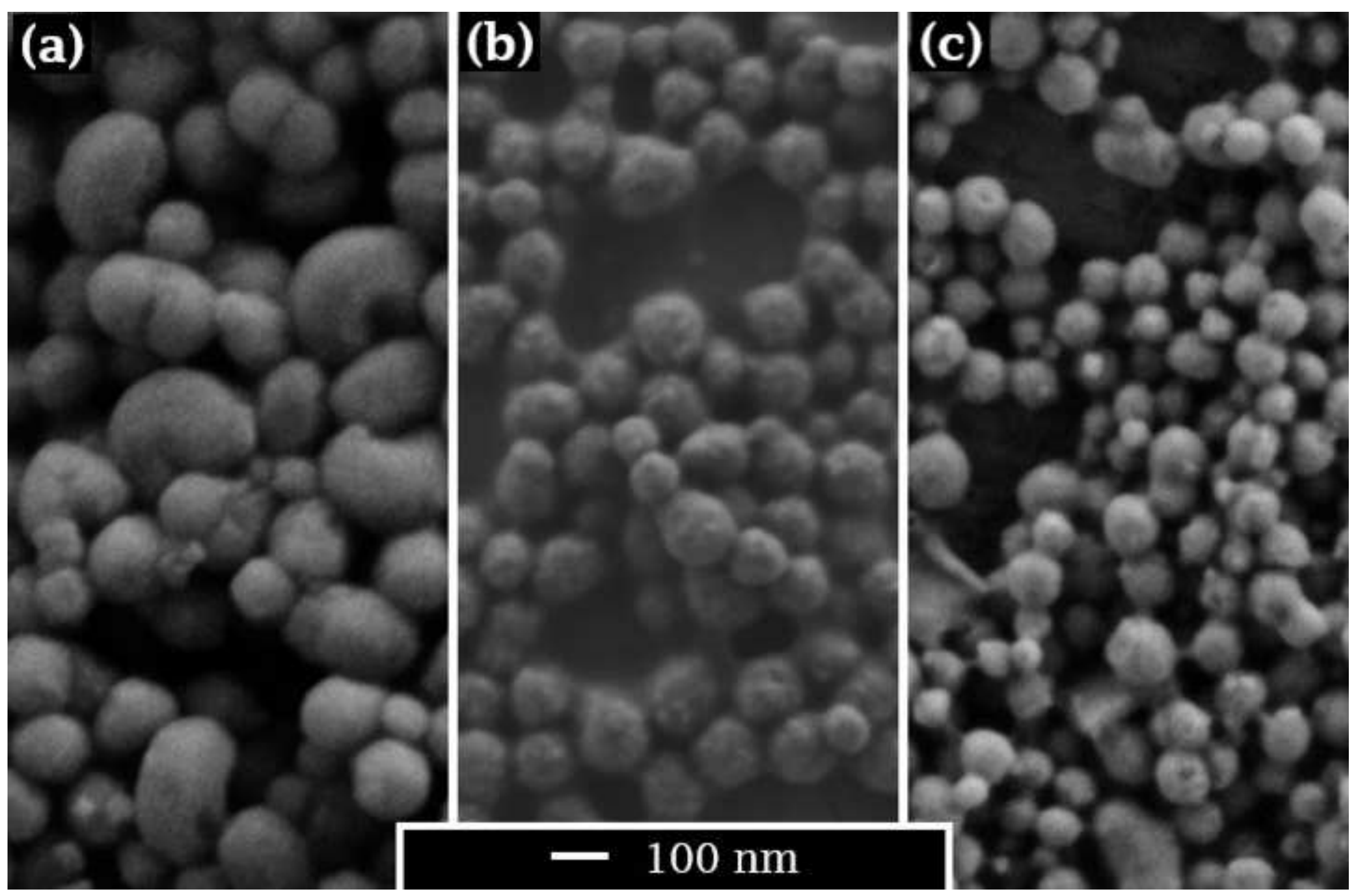




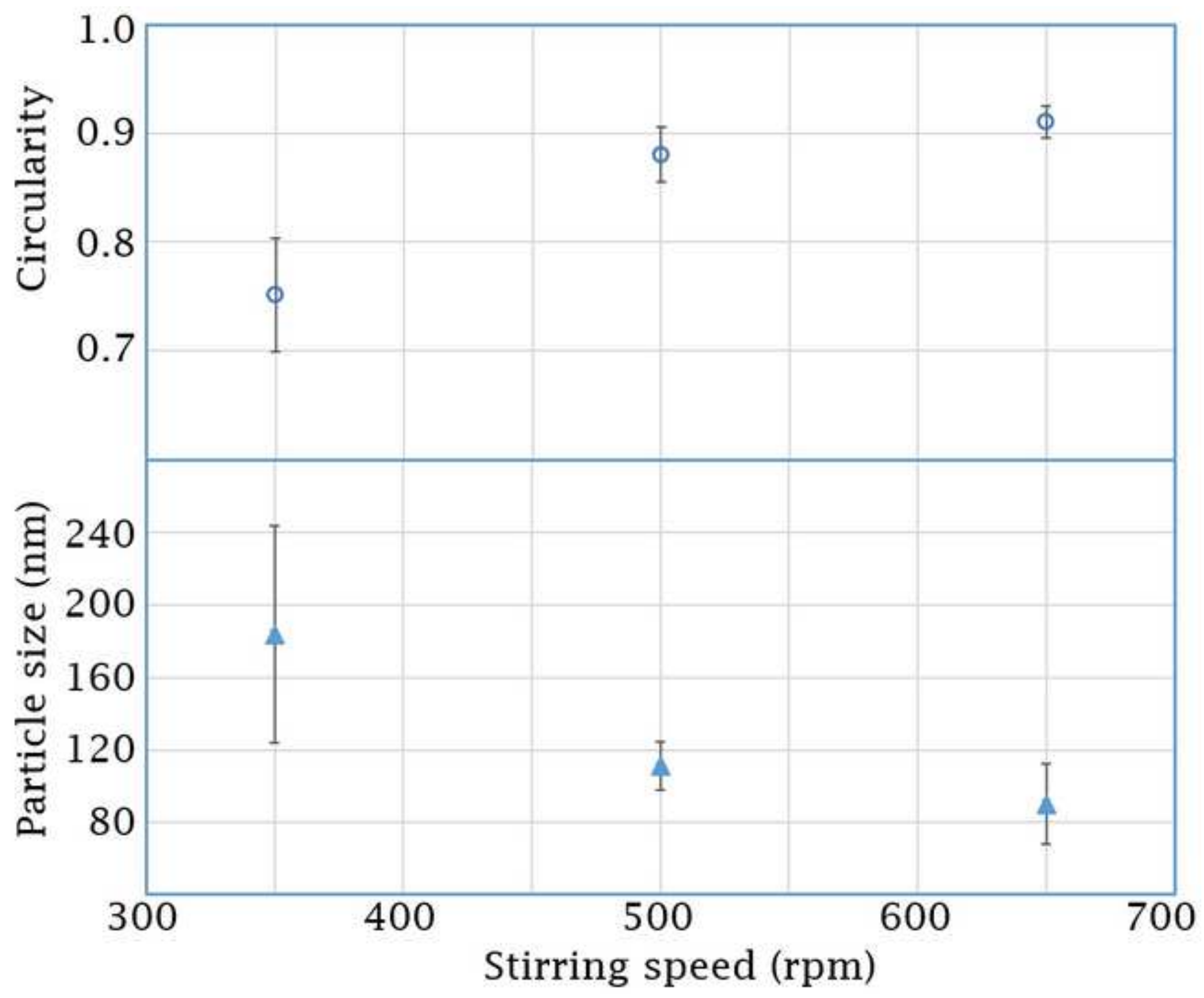




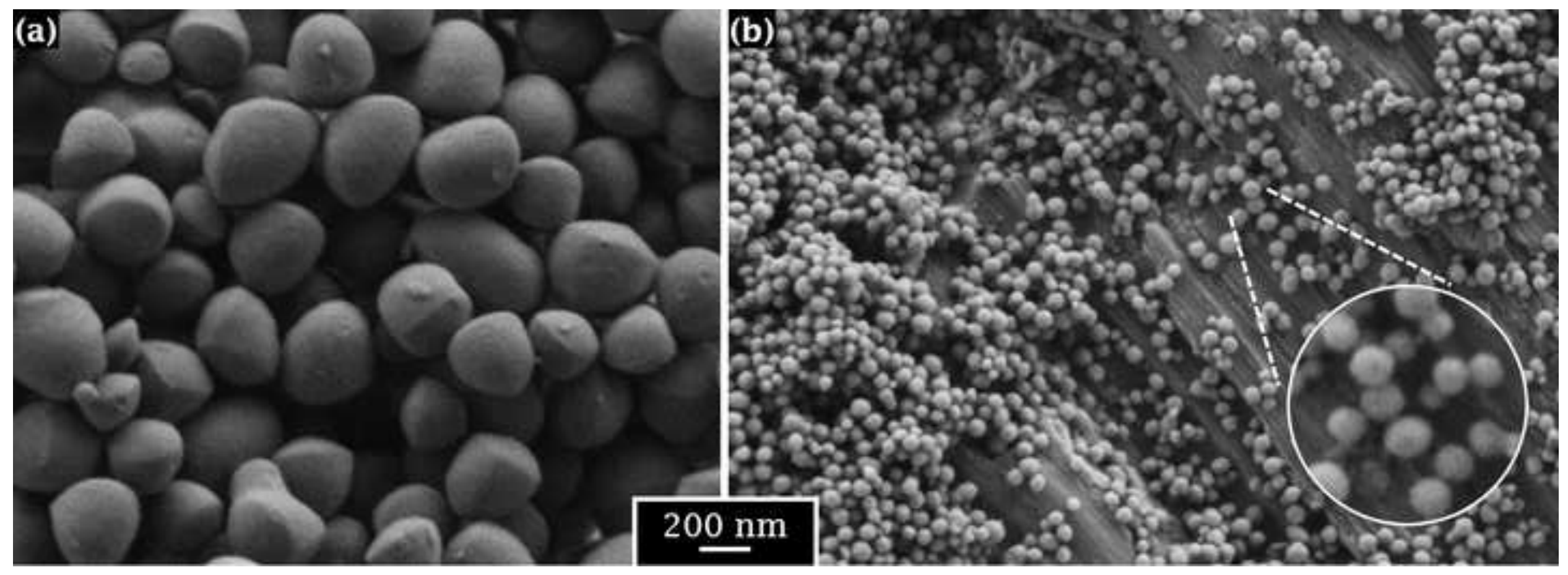




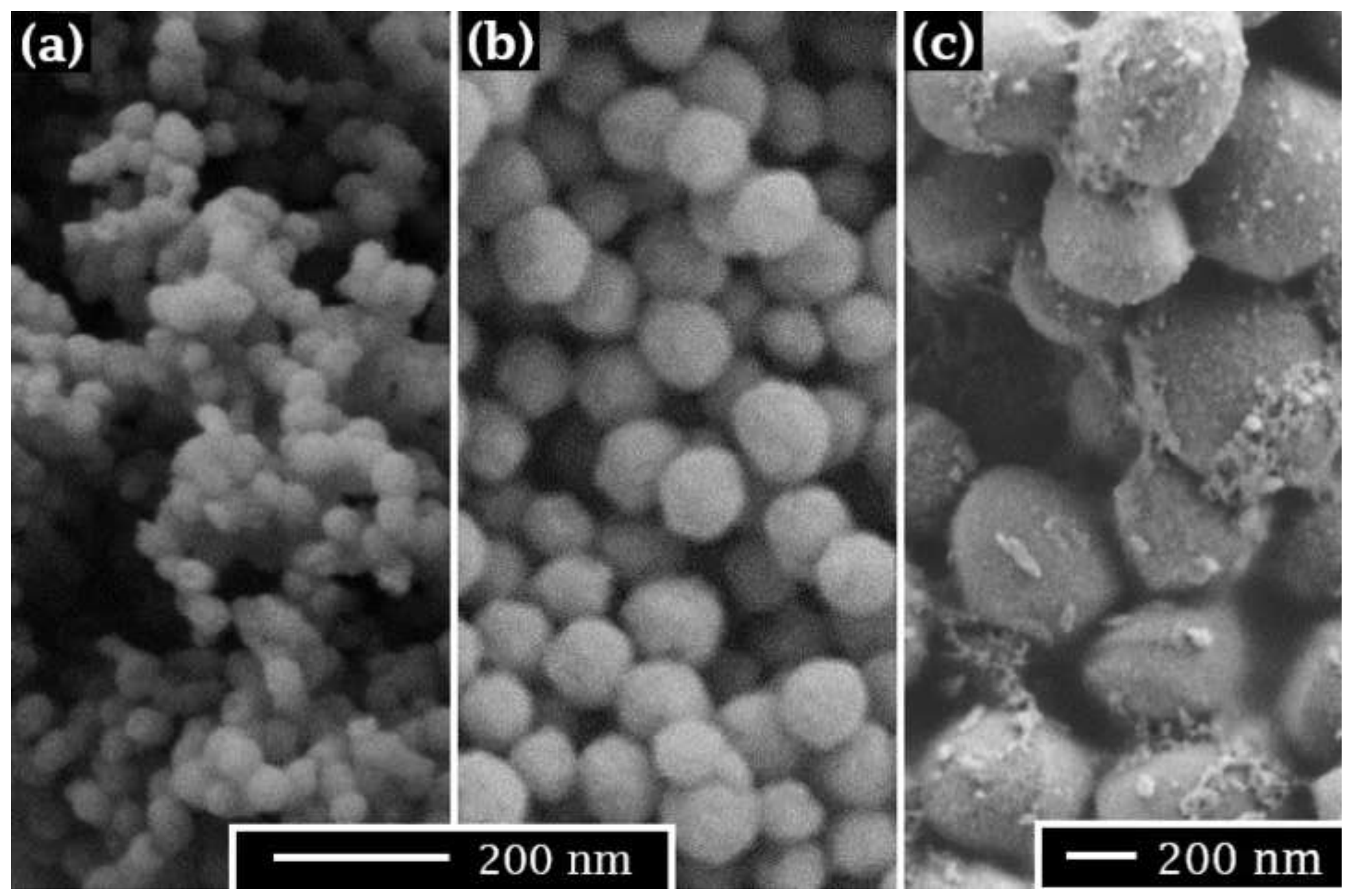




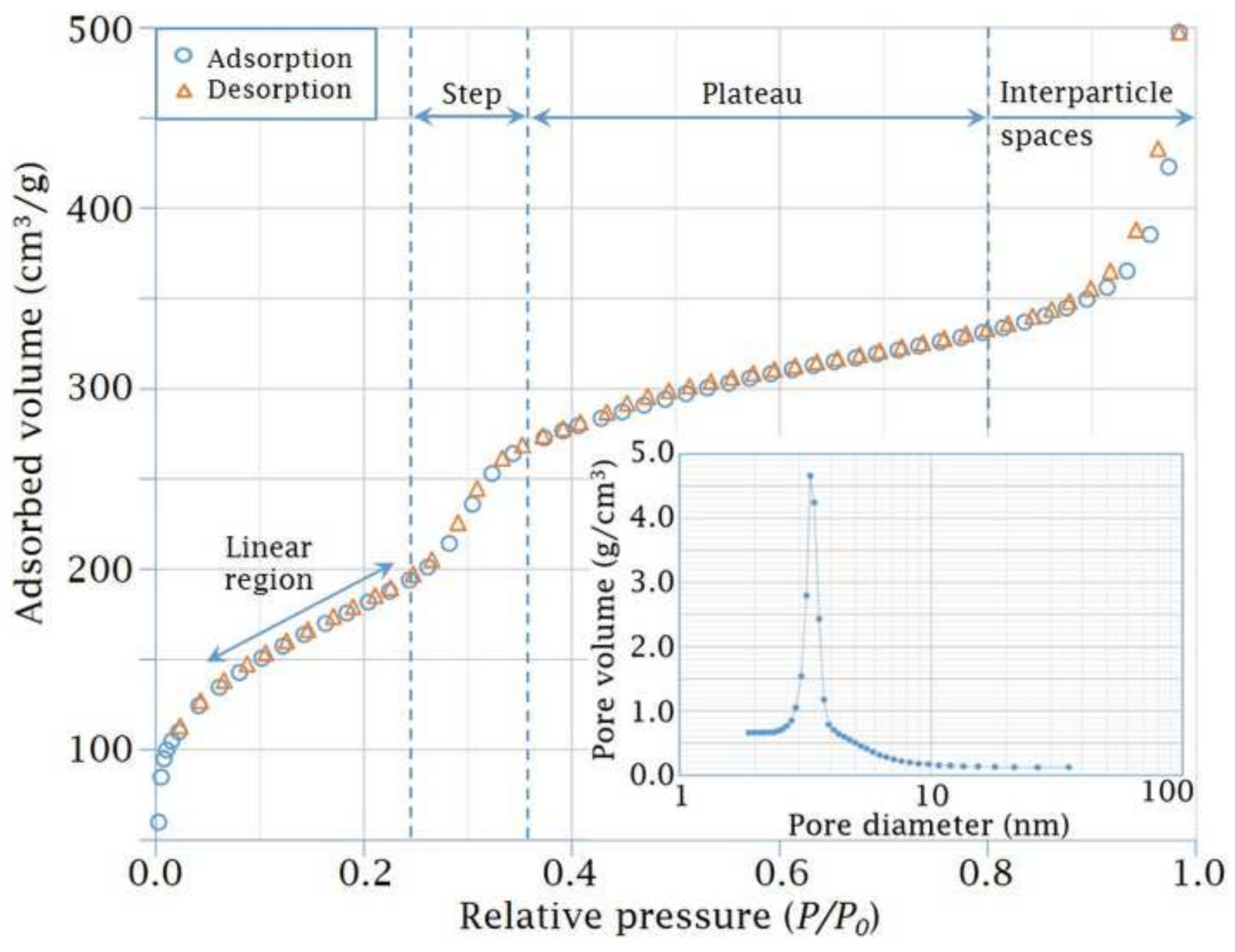



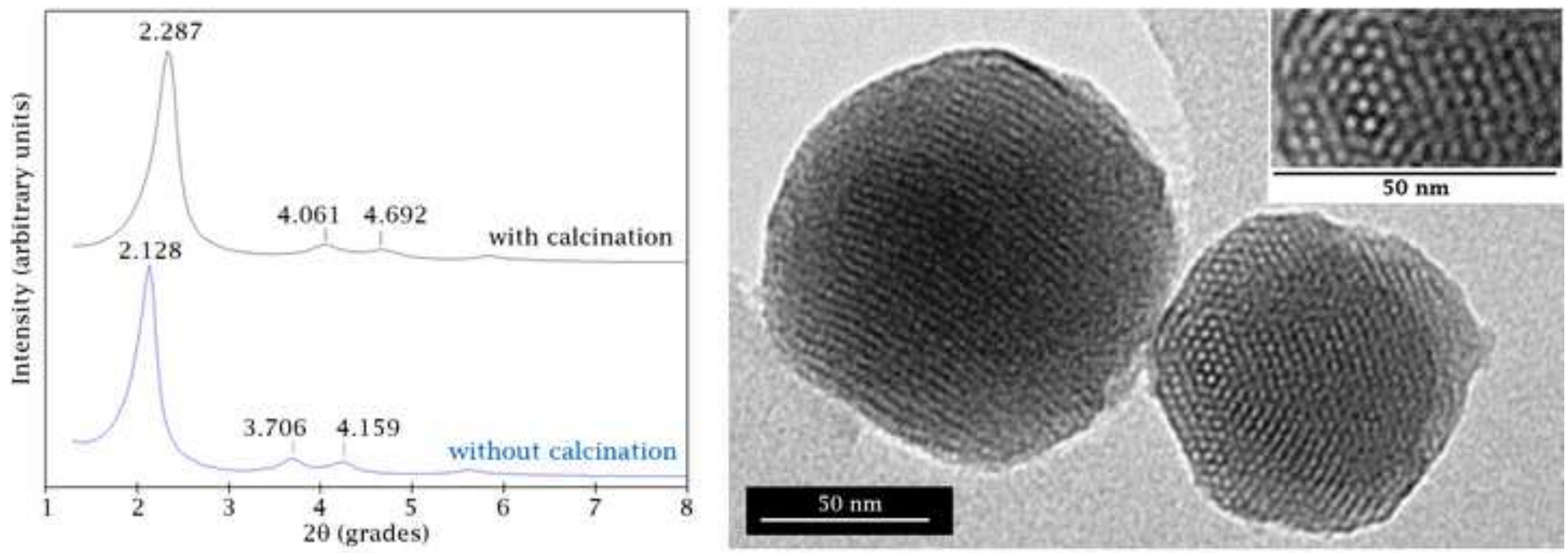


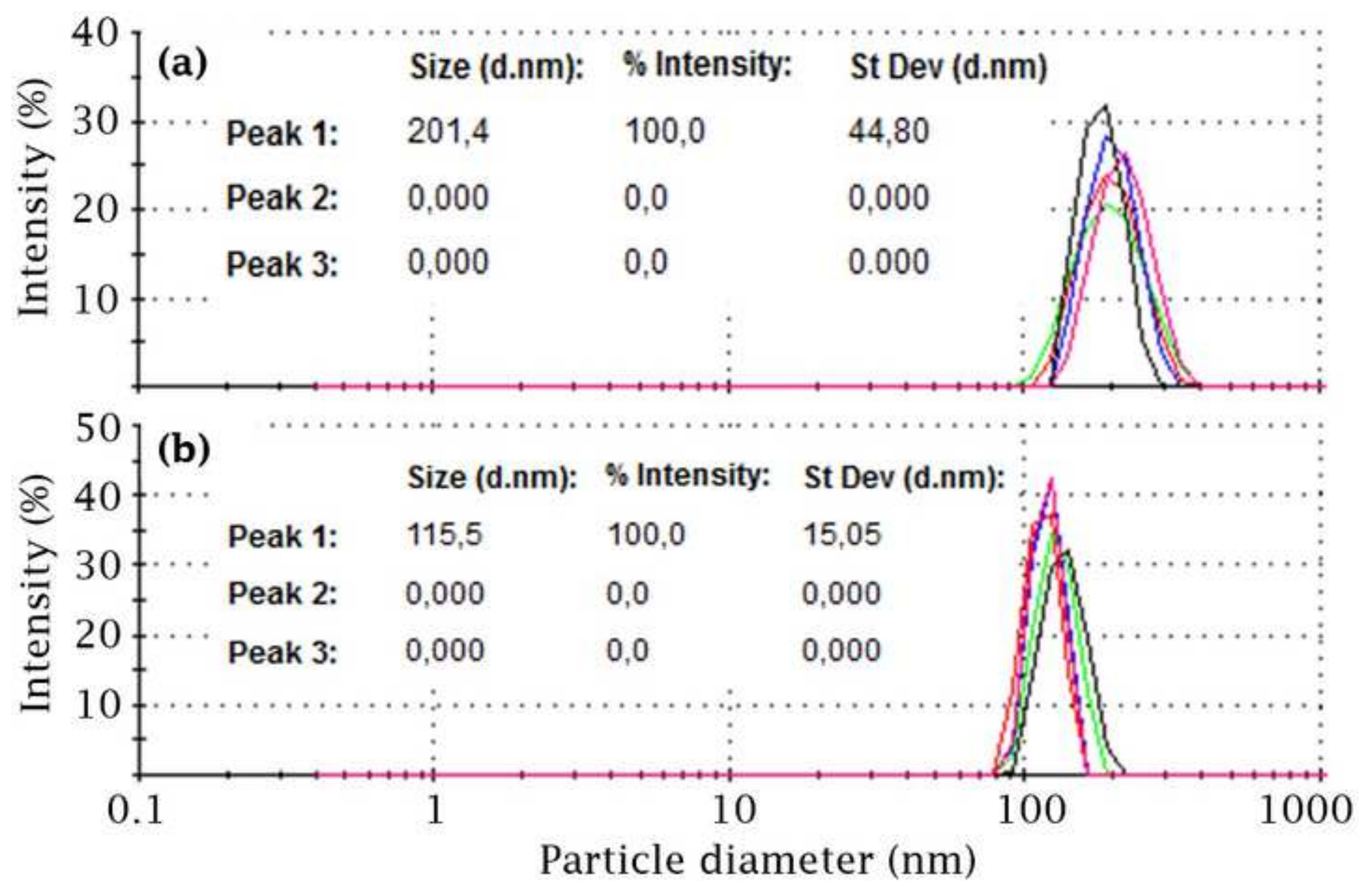

